\title{
The Continuing Search to Find a More Effective and Less Intimidating Way to Teach Research Methods in Higher Education
}

\author{
Robin Bell (r.bell@worc.ac.uk) \\ Innovations in Teaching and Education International (2016), Vol. 53, No. 3, pp. 285-295. \\ http://doi.org/10.1080/14703297.2014.956780
}

\begin{abstract}
Existing literature examining the teaching of research methods highlights difficulties students face when developing research competencies. Studies of student-centered teaching approaches have found increased student performance and improved confidence in undertaking research projects. To develop a student-centered approach, it could be beneficial to teach students through active participation, with the development of their research agendas as the basis for progression. To develop this goal, the research methods module for graduate students at a UK business school was restructured into a two-week block utilizing a student-centered approach. The performance of the students was then compared to the performance of students who undertook the same course material presented in a traditional semester-long module and the results were then statistically analyzed. The results of this study provide new and interesting evidence of increased student achievement and understanding through the new format and provide new avenues for future research.
\end{abstract}

\section{Keywords}

Research Methods, Intensive Course, Active Learning Environments 


\section{Introduction}

Existing literature acknowledges that university students find courses in research methods difficult and challenging, and students often perform poorly (Edwards \& Thatcher, 2004). Research methods courses are often unpopular with students because the course material is perceived to be complex and technical in nature, resulting in low student interest in the material (Ball \& Pelco, 2006) and a belief that learning research methods is difficult and irrelevant (Hubbell, 1994). Research has indicated that students struggle in research methods courses with developing 'intangible' aspects of research skills, including the development of a research disposition (Van der Rijst, Visser-Wijnveen, Verloop \& Van Driel, 2013).

In addition, courses are often focused on teaching theory rather than the application of research and are often delivered using a passive, lecture-based format (Benson \& Blackman, 2003). Students may thus form a poor perceptual link between learning research methods as an academic subject and the application of their learning to future studies (Benson \& Blackman, 2003). In addition, students may lack the skills necessary for the selection and use of qualitative and quantitative data collection and analysis procedures (Edwards \& Thatcher, 2004).

Nevertheless, the mastery of research methods is a critical skill in higher education, both to prepare students to undertake original research and to enable them to critically analyze research findings (Doyle \& Buckley, 2014; Zablotsky, 2001). Recent research has suggested that teaching research methods using passive, lecture-based approaches has met with limited success and can result in decreased student motivation and interest (Ball \& Pelco, 2006; Edwards \& Thatcher, 2004). As a result, attempts have been made to develop new approaches that students may find more accessible (Ball \& Pelco, 2006; Benson \& Blackman, 2003; Edwards \& Thatcher, 2004).

A UK business school has similarly observed that students struggle with understanding research methods and applying them to their own research and final-year dissertations. The business school accordingly adopted a new teaching approach that was designed to combine the advantages of an intensive format with increased participant engagement and a focus on independent learning. The new format was designed to help students increase their understanding of the subject matter and its applicability to their research and ultimately to improve grades in research methods courses.

\section{Literature review}

The advantages of intensive course design formats and active participant engagement are well described in the literature. This literature review considers these benefits and how they can aid in the development of effective course design. 


\section{Intensive course design}

Intensive courses have become increasingly common in universities to meet changing needs, including increasing numbers of non-traditional students seeking higher education (Austin \& Gustafson, 2006). The courses are usually structured in condensed formats that may include weekend and evening classes and work-based programs (Wlodkowski, 2003).

Scott (2003) suggested that, under the right conditions, which include an enthusiastic and experienced instructor, an active-learning and collegial atmosphere, classroom interaction, good course organization, student input, and a relaxed learning environment, intensive courses could have many benefits over a traditional format. These benefits include more focused learning, greater in-depth discussion, less procrastination, and stronger academic performance. The benefits may also encourage faculty to improve levels of interaction and discussion, which can increase student motivation and achievement (Kucsera \& Zimmaro, 2010).

Scott and Conrad (1992) reviewed fifty studies comparing intensive courses to traditional-length courses in many disciplines. They concluded that intensive courses resulted in largely equal or superior learning outcomes. Similarly, Van Scyoc and Gleason (1993) compared the outcomes of economics learning in a quantitative study and concluded that students taking a three-week course scored better than those taking a fourteen-week course, although there appeared to be no difference in knowledge retention. A review of the literature by Daniel (2000) compared intensive courses with traditional courses and concluded that intensive courses appear to yield equivalent or superior long- and short-term academic performance, with students expressing greater satisfaction with the intensive courses. Austin and Gustafson (2006) examined a database of 45,000 observations to conclude that intensive courses resulted in higher grades than did sixteen-week courses. They found that the benefit to students of an intensive course peaked at four weeks. By considering future performance, they showed that the higher grades were due to increased knowledge and not a lowering of standards during the shortened sessions.

Many reasons have been cited as to why intensive courses produce similar or superior outcomes to traditional formats. One reason is that students enrolled in intensive courses might be more highly motivated or develop a higher level of motivation than those in traditional courses (Windish, 1993). Another reason may be student preference. In a study comparing the effectiveness of intensive and traditional courses, Kucsera and Zimmaro (2010) found that while intensive courses did not significantly differ from traditional courses in students' instructor ratings, intensive courses received significantly higher course ratings overall, after controlling for class size and probable course grade. Intensive courses have been criticized as being too compressed to achieve consistent educational value. Another criticism is that they sacrifice breadth and depth, resulting in poorly-developed 
learning (Shafer, 1995). Doubts remain that intensive courses can produce the same results in less time than traditional education formats, based on the belief that longer face-to-face classroom meeting time produces a more effective learning experience (Reardon, Payan, Miller \& Alexander, 2008). Other arguments against intensive courses include insufficient time to cover syllabi, reduced contact time with instructors that is necessary for analysis of the taught content, decreased academic rigor, and the risk of increased stress and reduced student satisfaction. It has also been argued that higher education institutions may adopt intensive courses for student convenience and to increase enrolment, rather than to improve students' learning experience (Scott, 2003; Wlodkowski, 2003). Nevertheless, evidence suggests that intensive course formats can provide outcomes equally effective to, if not more effective than, traditional formats (Wlodkowski \& Westover, 1999).

\section{Active learning environments}

The literature suggests that students learn research methods best by actively engaging in the subject matter. Nixon and Williams (2014) found effective curriculum design to be a crucial aspect of student engagement. Hubbell (1994) found that statistical formulae and theoretical concepts meant little to students who lacked an environment in which they could actively participate. This sentiment was echoed by Fallows and Ahmet (1999), who argued that students could most effectively learn when their involvement, participation, and interaction with module materials and concepts were maximized. Research suggests that a more student-centered approach, can result in improved student performance and increased student satisfaction, with students reporting they felt more stimulated and better prepared to conduct research in the future (Ball \& Pelco, 2006; Edwards \& Thatcher, 2004). Edwards and Thatcher (2004) found that active engagement via seminars and the opportunity for continual assessment throughout the course by instructors contributed to improved student performance.

Ames (1992) argued that students would be more likely to fully engage in learning if they perceived meaningful reasons for participating in an activity. Meaningful reasons include developing an understanding of the activity content and improving or gaining new skills. Students are also more likely to fully engage in their learning when they find assignments and presentations meaningful and personally relevant (Meece, 1991). Piercy (2013) found that students perceive an applied workshop experience to be both engaging and personally relevant, providing a better incentive to learn than the traditional lecture format.

In order to move towards an active-participant learning environment, it is necessary to adapt the role of the instructor. Instructors should initiate, encourage, and support student ownership of their 
learning processes (Benson \& Blackman, 2003) and be encouraged to undertake activity-based learning. By implementing a program that allows space for reflection and feedback via peer groups, instructors will encourage and aid students' learning (Beveridge, 1997). Structured approaches to reflection can enhance the process (Platzer, Snelling, \& Blake, 1997).

Instructors frequently use group work and group presentations to engage students, and an extensive body of literature supports their benefits in higher education (Nordberg, 2008; Plastow, Spiliotopoulou, \& Prior, 2010). These benefits include the ability to develop transferable and subjectspecific skills (Wisker, 1994) and the active involvement they provide in the student learning process (Matveev \& Milter, 2010). Whilst some studies have suggested that students responded positively to group activities (Cadiz Dyball, Reid, Ross, \& Schoch, 2007), others have suggested that students were less satisfied with their group work experiences (Shah, 2013).

The literature outlines the benefits of an intensive course design which include increased student performance (Austin \& Gustafson, 2006; Daniel, 2000; Scott \& Conrad, 1992; Van Scyoc \& Gleason, 1993) and increased student satisfaction (Kucsera \& Zimmaro, 2010; Windish, 1993). Furthermore, research has found that students are better able to learn research methods in an active learning environment (Ball \& Pelco, 2006; Edwards \& Thatcher, 2004; Hubbell, 1994; Nixon \& Williams, 2014). This research aims to combine the potential advantages of an intensive format with studentcentered learning and active engagement in research methods education. The features of the new course design are detailed in Table 1. 
Table 1. Course Design Considerations Based on Existing Literature

\begin{tabular}{lll}
\hline Issues & Potential Solutions & Feature of New Course Design \\
\hline \multicolumn{2}{l}{ Research Methods Course Design } & \\
\hline Passive teaching approaches & Active participation in course & $\begin{array}{l}\text { Students worked with peer } \\
\text { groups based on their topics of } \\
\text { interest }\end{array}$ \\
& & Learning and group discussions \\
\hline Theory-based course design & Activity-based learning & centered around students' \\
& incorporating constructive and & individual research ideas \\
\hline $\begin{array}{l}\text { Often taught over the course } \\
\text { of a semester, which can }\end{array}$ & Teach research methods in a & Two-week intensive course to \\
hinder the comprehension of & format & deliver integrated sessions and \\
a complete picture & & provide a focused learning \\
& & environment
\end{tabular}

\section{Student Understanding of the Research Methods Process}

\begin{tabular}{|c|c|c|}
\hline $\begin{array}{l}\text { Research methods course } \\
\text { material perceived as difficult } \\
\text { and technical }\end{array}$ & $\begin{array}{l}\text { Use small groups learning to } \\
\text { increase student interaction }\end{array}$ & $\begin{array}{l}\text { Students received peer feedback } \\
\text { regularly and undertook two } \\
\text { formative assessments }\end{array}$ \\
\hline $\begin{array}{l}\text { Difficulty in identifying } \\
\text { appropriate quantitative and } \\
\text { qualitative data } \\
\text { collection/analysis techniques }\end{array}$ & $\begin{array}{l}\text { Practical application of data } \\
\text { collection and analysis to 'real' } \\
\text { projects }\end{array}$ & $\begin{array}{l}\text { Students taught theoretical } \\
\text { strengths/weaknesses of } \\
\text { different methods and were } \\
\text { expected to justify their choice }\end{array}$ \\
\hline $\begin{array}{l}\text { Students inadequately } \\
\text { prepared to undertake } \\
\text { dissertation research }\end{array}$ & $\begin{array}{l}\text { Provide the opportunity for } \\
\text { students to discuss and develop } \\
\text { their own research ideas in a } \\
\text { supported environment }\end{array}$ & $\begin{array}{l}\text { Students discussed their } \\
\text { proposals with subject specialists } \\
\text { daily, increasing feedback and } \\
\text { reflection }\end{array}$ \\
\hline
\end{tabular}

\section{Research design}

Instructors of research methods courses at a UK business school observed that students struggled with the course content and the perceived complexity of the course material, which was delivered via weekly lectures and seminars over a 12 -week period. Students struggled with conceptualizing the course content and applying it to their research projects. Subsequently, students often received relatively low grades on their two assignments. Drawing from existing research (Fallows \& Ahmet, 
1999; Matveev \& Milter, 2010; Piercy, 2013) the business school implemented a new, intensive course format, aiming to increase student participation, increase the relevancy of the teaching, and promote independent learning in a less formal and more collegiate environment. Importantly, students were encouraged to develop constructive and reflective practices by allowing time for reflection and feedback throughout the process, as discussed by Beveridge (1997). The new teaching format condensed the course teaching into a two-week intensive block, conducted before the start of the second semester. The intended learning outcomes and details of the summative assessment are detailed in Table 2.

Table 2. Intended Learning Outcomes \& Module Assessments Intended Learning Outcomes

To be able to:

1. Evaluate the strengths and weaknesses of particular research approaches and methodologies

2. Formulate research questions and aims/hypotheses as appropriate

3. Design research methods to achieve stated research aims

4. Critically evaluate research methods against given aims/hypotheses

Summative Module Assessment

Intended Learning

Outcome Assessed

\begin{tabular}{llr}
\hline $\begin{array}{l}\text { Assignment 1- Research } \\
\text { Critique }\end{array}$ & $\begin{array}{l}\text { Evaluation of a published peer } \\
\text { reviewed paper }\end{array}$ & 1,4 \\
$\begin{array}{l}\text { Assignment 2 - Research } \\
\text { Proposal }\end{array}$ & $\begin{array}{l}\text { Development of a research } \\
\text { proposal }\end{array}$ & 2,3
\end{tabular}

The first stage of course development required the written course material to be sent to the students electronically to allow them to review it prior to the start of the course. The teaching was then carried out over a two-week period in fifteen- to twenty-minute instructor-led presentations that were followed by a practical activity wherein students developed a set of methods suitable for their own research project. Their methodological decisions were discussed within small peer groups and then with the entire class. Two optional sessions with an instructor were available for the students to individually discuss their proposals and check that their methodological approaches 
were appropriate. Sample research questions were available for reference during the optional sessions to aid any student struggling with conceptualizing his/her own research question.

This format covered the entire syllabus and took students through each stage of the research process, enabling them to critically analyze many research approaches. Instructors helped students understand why some approaches and methods were more suitable and why other approaches and methods were less suitable. Students were thus better able to develop the research methods most suitable for their dissertations. A further advantage of this approach was that the students were able to obtain feedback and learn from their errors after each stage of the process by interacting regularly with their groups and instructors.

The outcome of the change in course format was measured by a quantitative analysis of the grades achieved from the two assessments, which were compared to grades from the previous year's courses. In addition, qualitative feedback was obtained from the students' dissertation supervisors regarding students' preparedness to conduct their research.

\section{Research ethics}

The project was conducted using best ethical practice. Student performance was recorded anonymously using students numbers, stored in accordance with the United Kingdom Data Protection Act 1998, and care was taken to ensure a fair and accurate representation of the results (Saunders, Lewis, \& Thornhill, 2011). The ethics of changing teaching methods warranted consideration; however, the changes were introduced to bring student performance to a desired standard. Hopkins (2008) suggests that, while improvement through innovation should be supported, improving teaching should be the primary objective and research should not hinder education of the students. Sound reasons from the literature supported the belief that the new format would enhance student learning.

\section{Methodology and results}

The new, intensive, two-week research methods course was run for the 2012-13 academic year ( $\mathrm{n}=$ 45). The overall module grade for each participant (calculated from the two course assignments) was then compared to grades obtained in the previous academic year by students completing the same two assignments within the traditional 12-week course $(n=51)$. The assessment scores used in the analysis were both internally and externally moderated, which should ensure consistency between the scores over the two years. The data was then subjected to an independent sample t-test to determine whether a significant difference existed between the mean score of the intensive course 
students and the score from the previous year. A summary of the results is shown in Table 3 and Table 4.

Table 3. Independent Sample t-test Group Statistics

\begin{tabular}{lcccc} 
Course Studied & N & Mean & Std. Deviation & Std. Error Mean \\
\hline New Format Class Score (2012/13) & 45 & 56.47 & 11.23 & 1.67 \\
Traditional Class Score (2012/13) & 51 & 51.18 & 9.33 & 1.31 \\
\hline
\end{tabular}

Table 4. Independent Sample t-Test Results

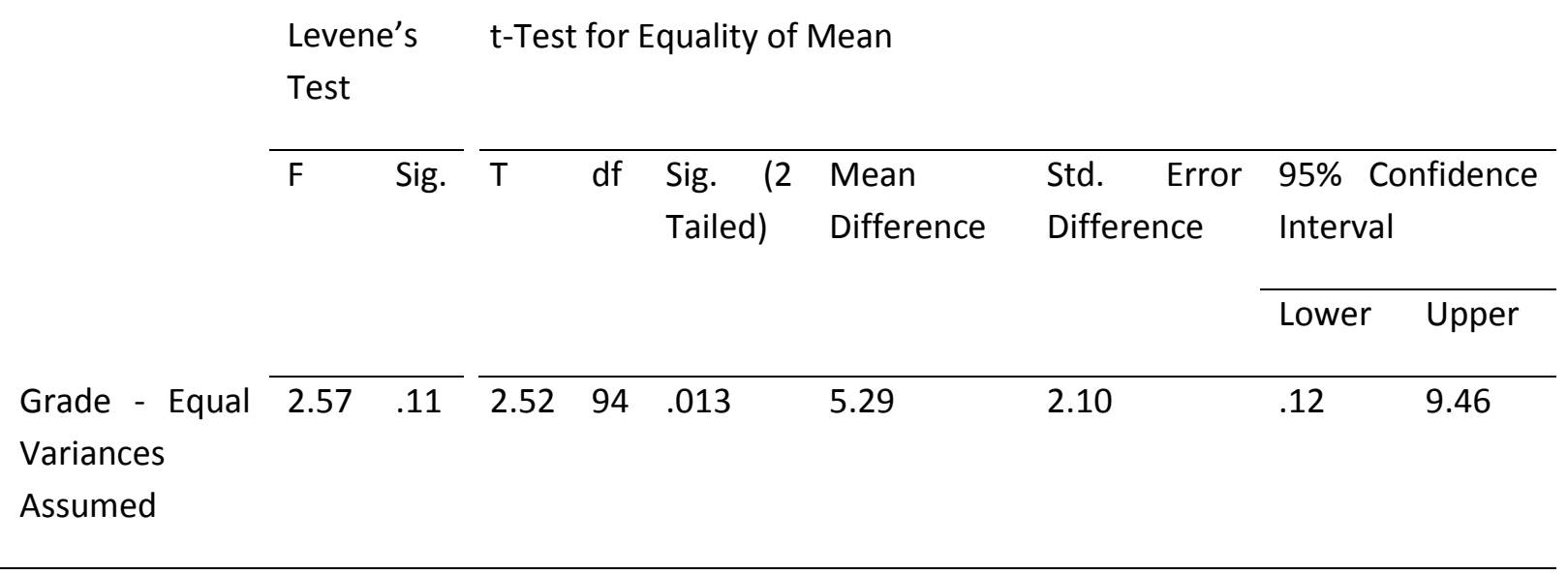

The results in Table 4 indicate that a significant difference at a 95\% confidence level exists between the overall scores achieved in the new class format and those in the traditional format. The results in Table 3 confirm that the mean score for the new format $(56.47)$ is greater than that for the traditional format (51.18) in this sample. Interestingly, the standard deviation of scores is greater in the new format than the traditional format. This may be a characteristic of the cohorts or could indicate that some students benefited from the new format whilst others struggled.

To provide a deeper analysis of the scores, paired t-tests were undertaken between the individual student scores and the average scores for the other previous courses each student had sat as part of their program of study. The tests highlight how students performed on the research methods module compared to other courses, which were delivered in a variety of formats. The test considered the ability of individual students and gave an indication of achievement against individual ability, as measured across a range of previous courses. The results of the paired t-tests are shown in tables 5-8. 
Table 5. Paired Samples t-test Group Statistics - New Format

\begin{tabular}{lcccc} 
Score & N & Mean & Std. Deviation & Std. Error Mean \\
\hline Research Methods Score & 45 & 56.47 & 11.23 & 1.67 \\
Average Score & 45 & 55.61 & 7.80 & 1.16 \\
& & & & \\
\hline
\end{tabular}

Table 6. Paired Samples t-Test Results - New Format

Paired Differences

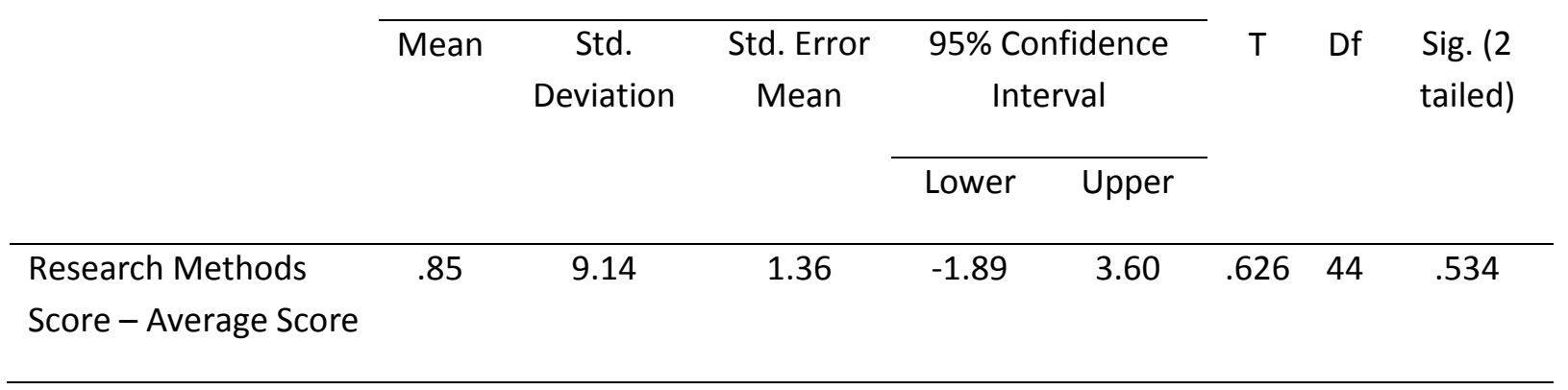

Table 7. Paired Samples t-test Group Statistics - Traditional Format

\begin{tabular}{lcccc} 
Score & N & Mean & Std. Deviation & Std. Error Mean \\
\hline Research Methods Score & 51 & 51.18 & 9.33 & 1.31 \\
Average Score & 51 & 57.55 & 5.84 & .82 \\
\hline
\end{tabular}

Table 8. Paired Samples t-Test Results - Traditional Format

\begin{tabular}{|c|c|c|c|c|c|c|c|c|}
\hline & \multicolumn{5}{|c|}{ Paired Differences } & \multirow{3}{*}{$\mathrm{T}$} & \multirow{3}{*}{ Df } & \multirow{3}{*}{$\begin{array}{l}\text { Sig. (2 } \\
\text { tailed) }\end{array}$} \\
\hline & \multirow[t]{2}{*}{ Mean } & \multirow[t]{2}{*}{$\begin{array}{c}\text { Std. } \\
\text { Deviation }\end{array}$} & \multirow{2}{*}{$\begin{array}{l}\text { Std. } \\
\text { Error } \\
\text { Mean }\end{array}$} & \multicolumn{2}{|c|}{$\begin{array}{l}\text { 95\% Confidence } \\
\text { Interval }\end{array}$} & & & \\
\hline & & & & Lower & Upper & & & \\
\hline Research Methods & -6.37 & 7.31 & 1.02 & -.8 .43 & -4.31 & -6.22 & 50 & .000 \\
\hline Score-Average & & & & & & & & \\
\hline Score & & & & & & & & \\
\hline
\end{tabular}

The results indicate the following. With regard to the traditional course, there was a significant difference between the research methods scores and the students' overall average scores (51.18 
against 57.55). There was also a larger standard deviation in the scores from the research methods course compared to the average grade scores. Regarding the new course format, it was found that no statistical difference existed between the research methods and the students' average overall scores (56.47 against 55.61). Once again, the standard deviation in the research methods course scores was larger than for the average student scores. Based on these findings, it would appear that whilst the average overall scores have remained relatively similar (2011-12, 57.55 against 2012-13, 55.61), the research methods scores have shown a statistically significant increase for the new format (2011-12, 51.18 against 2012-13, 56.47). The data suggest that the students performed better in the newly formatted research methods module when compared to the traditional format, and more in line with the students' overall average scores.

Additional evidence was collected from interviews following the intensive courses with five faculty members who supervised the students' research projects (dissertations). The interviewees had also supervised the research projects of students who had undertaken the traditional research methods during the previous year. The interviews elicited the faculty members' views regarding students' preparedness to conduct research and general understanding of research methods. The main points emerging from the interviews are summarized below:

Positive comments:

- Students came prepared with ideas to discuss, making the initial meeting more productive.

- The proposed methods could be defended and justified, reflecting deeper knowledge and understanding.

- Projects were outlined, and students had a realistic idea of what was required regarding the stages and timing.

- Students had a better understanding of their proposed research topics.

- Students were enthusiastic and took greater ownership of their projects.

Negative Comments

- Some students had difficulty thinking up new ideas.

- Students found it difficult to deviate from a linear path and overcome obstacles.

- Proposed project topics were too similar between students.

- Students were often set on their proposed ideas and seemed resistant to change. 


\section{Analysis and Conclusions}

The desired outcome of the new format was to improved assignment scores, enable a more comprehensive understanding of the course material, and, enable students to produce better dissertations. The following tentative conclusions can be drawn from the findings. The new format produced scores that were at least as good as the traditional format and which were more closely aligned with students' average overall course scores. Subsequently, students were often able to come to their initial supervisory meetings prepared with ideas regarding their research plans. They had a clearer idea of the research process and were often enthusiastic and more prepared to take ownership of their project. The findings provide additional evidence to support existing research arguing that an intensive format and high levels of participant engagement are advantageous to the learning process.

The improvements in the students' performance on their assignments may be attributed to the compressed format and focused learning, which helped students to make the perceptual link between the taught content and an applied project. The active learning environment enabled greater in-depth discussion, shown by Kucsera and Zimmaro (2010) to increase student achievement, and gave students the opportunity to apply their learning throughout the course.

The feedback from the interviews suggests that the students were better able to overcome the perceptual link between learning research methods as a subject and then using the knowledge in practice. This was a key barrier to students' understanding of research methods, identified by Benson and Blackman (2003). Overcoming this barrier could decrease the perception that learning research methods is irrelevant and difficult (Hubbell, 1994).

There was, however, a greater standard deviation in the new course format scores than with both the traditional format course and the average course scores. This could be a reflection on the cohort samples or may signify a larger variation in how students responded to the new format, suggesting that certain students may benefit more greatly from this format whilst others may find it more difficult. Although group learning can be beneficial to weaker students by helping to support their self-esteem and facilitating their learning (Crooks, 1988), certain student groupings may still find it difficult to participate in active engagement. This may, in part, reflect the variation in the results reported in the literature regarding the attitude of students towards group activities (Cadiz Dyball et al., 2007; Shah, 2013; \& Piercy, 2013). Due to the limited size of this project, it is not possible to investigate this further.

Other concerns expressed included the difficulty in moving away from a linear thought path and a resistance to different approaches and ideas. The concerns could reflect a less developed understanding and knowledge of alternative options, which may develop once the student clarifies 
his/her idea. This highlights the importance of teaching and engaging students on the whole syllabus to ensure overall understanding of the subject matter.

In common with all research, this project has several limitations. While increasing the size of the groups would have produced stronger and more generalizable evidence, the statistical analysis provides a sound basis for future research to extend the principles and conclusions drawn from this research. Similarly, this research was conducted across two years, which may have made the results less comparable. Additionally, this research only considered the effects of the changes in terms of student achievement and did not account for the students' experience and satisfaction, which could have highlighted the particular aspects that students found difficult and could have been used to make amendments to the teaching format in the future. However, interestingly, it should be noted that routine post course student satisfaction surveys conducted at the end of both courses indicated similar levels of student satisfaction. Finally, by introducing a number of changes at the same time in a teaching program, it is not possible to pinpoint which of the individual changes had the greatest impact on the student achievement. However, since the objective of this research was to combine the potential advantages of an intensive format, a high level of active engagement, and a focus on independent learning, this does not weaken the conclusions of this research.

In conclusion, after a research methods course was redesigned to combine the advantages of an intensive format with an active learning environment focused on participant engagement, it appears to have; resulted in improved assessment scores and a greater ability of students to apply their learning to research projects. Furthermore, the new format adopted in the research study provides new and interesting avenues for future research. 


\section{References}

Ames, C. (1992). Classrooms: Goals, structures, and student motivation. Journal of Educational Psychology, 84(3), 261-71.

Austin, A. M., \& Gustafson, L. (2006). Impact of course length on student learning. Journal of Economic and Finance Education, 5(1), 26-37.

Ball, C. T., \& Pelco, L. E. (2006). Teaching research methods to undergraduate psychology students using an active cooperative learning approach. International Journal of Teaching and Learning in Higher Education, 12(2), 147-154.

Benson, A., \& Blackman, D. (2003). Can research methods ever be interesting? Active Learning in Higher Education, 4(1), 39-55.

Beveridge, I. (1997). Teaching your students to think reflectively: The case for reflective journals. Teaching in Higher Education, 2(1), 33-44.

Cadiz Dyball, M., Reid, A., Ross, P., \& Schoch, H. (2007). Evaluating assessed group-work in a secondyear management accounting subject. Accounting Education, 16(2), 145-162.

Crooks, T. J. (1988). The impact of classroom evaluation practices on students. Review of Educational Research, 58(4), 438-481.

Daniel, E. L. (2000). A review of time-shortened courses across disciplines. College Student Journal, 34(2), 298-308.

Doyle, E., \& Buckley, P. (2014). Research ethics in teaching and learning. Innovations in Education and Teaching International, 51(2), 153-163.

Edwards, D. F., \& Thatcher, J. (2004). A student-centred tutor-led approach to teaching research methods. Journal of Further and Higher Education, 28(2), 195-206.

Fallows, S., \& Ahmet, K. (1999). Inspiring students: Case studies in motivating the learner. London: Kogan Page/Staff and Educational Development Association.

Hopkins, D. (2008). A teacher's guide to classroom research. London: Open University Press.

Hubbell, L. (1994). Teaching research methods: An experiential and heterodoxical approach. Political Science and Politics, 27(1), 60-64.

Kucsera, J. V., \& Zimmaro, D. M. (2010). Comparing the effectiveness of intensive and traditional courses. College Teaching, 58(2), 62-68.

Matveev, A.V., \& Milter, R.G. (2010). An implementation of active learning: Assessing the effectiveness of the team infomercial assignment. Innovations in Education and Teaching International, 47(2), 201-213.

Meece, J. (1991). The classroom context and children's motivational goals. In M. Maehr \& P. Pintrich 
(Eds.), Advances in Achievement Motivation Research (Vol. 7, pp. 261-286). Greenwich, CT: JAI Press.

Nixon, S., \& Williams, L (2014). Increasing student engagement through curriculum redesign: Deconstructing the 'Apprentice' style of delivery. Innovations in Education and Teaching International, 51(1), 26-33.

Nordberg, D. (2008). Group projects: More learning? Less fair? A conundrum in assessing postgraduate business education. Assessment \& Evaluation in Higher Education, 33(5), 481-492.

Piercy, N. (2013). Evaluating experiential learning in the business context: Contributions to groupbased and cross-functional working. Innovations in Education and Teaching International, 50(2), 202-213.

Plastow, N., Spiliotopoulou, G., \& Prior, S. (2010). Group assessment at first year and final degree level: A comparative evaluation. Innovations in Education and Teaching International, 47(4), 393-403.

Platzer, H., Snelling, J., \& Blake, D. (1997). Promoting reflective practitioners in nursing: A review of theoretical models and research into the use of diaries and journals to facilitate reflection. Teaching in Higher Education, 2(2), 103-121.

Reardon, J., Payan, J., Miller, C., \& Alexander, J. (2008). Optimal class length in marketing undergraduate classes: An examination of preference, instructor evaluations, and student performance. Journal of Marketing Education, 30(1), 12-20.

Saunders, M., Lewis, P., \& Thornhill, A. (2011). Research methods for business students. Harlow: FT/Prentice Hall.

Scott, P. A. (2003). Attributes of high-quality intensive courses. New Directions for Adult and Continuing Education, 2003(97), 29-38.

Scott, C., \& Conrad, P. A. (1992). A critique of intensive courses and an agenda for research. In J. Smart (Ed.), Hand Book of Theory and Research (pp. 411-459). New York: Agathon Press.

Shafer, D. W. (1995). A qualitative study of adult and traditional college students' perceptions of a compressed and traditional length college course (Unpublished Doctoral Thesis). Boston University, Boston, MA.

Shah, S. Z. A. (2013). The use of group activities in developing personal transferable skills. Innovations in Education and Teaching International, 50(3), 297-307.

Van der Rijst, R., Visser-Wijnveen, G., Verloop, N., \& Van Driel, H (2013) Undergraduate science coursework: Teachers' goal statements and how students experience research. Innovations in Education and Teaching International, 50(2), 178-190. 
Van Scyoc, L., \& Gleason, J. (1993). Traditional or intensive course lengths? A comparison of outcomes in economics learning. Journal of Economic Education, 24(1), 15-22.

Windish, C. E. (1993). Motivation of intensive English program participants: A factor analytic exploration. Georgia State University.

Wisker, G. (1994). Innovative assessment: Peer group and oral assessment. Innovations in Education \& Training International, 31(2), 104-114.

Wlodkowski, R. J. (2003). Accelerated learning in colleges and universities. New Directions for Adult and Continuing Education, 2003(97), 5-16.

Wlodkowski, R. J., \& Westover, T. N. (1999). Accelerated courses as a learning format for adults. Canadian Journal for the Study of Adult Education, 13(1), 1-20.

Zablotsky, D. (2001). Why do I have to learn this if I'm not going to graduate school? Teaching research methods in a social psychology of aging course. Educational Gerontology, 27(7), 609622. 